\title{
Historical review of croup
}

\author{
Victor Marchessault MD FRCPC
}

\section{$\mathrm{I}^{\mathrm{n}}$}

n the 1960s, managing croup was simple - put the child in the bathroom and run a hot shower. In most cases, the child's symptoms would be controlled. When the mist from the shower failed to control the croup, the parents would take the child to an emergency room. Often, the child would get better on the way to the hospital, thanks to the cool, outside air. At the hospital, a 'croupette' would be available for some children, and the health care providers hoped that the children would remain quiet in the strange tent filled with cold mist. Some hospitals even had special croup rooms where steam was piped in, and the whole room was filled with cold mist. Needless to say, nursing staff were not eager to work in these rooms. The last resort of treatment was a tracheotomy because the art of intubation had not yet been mastered. Two randomized studies failed to show the benefit of cool mist, and, today, it is rarely used $(1,2)$.

Historically, croup referred to a spasmodic type of cough, with the sudden onset of a barking cough in the middle of the night in a child about two years of age who had been well at bedtime the previous evening. In French, this condition was called 'faux-croup' because the word 'croup' referred to diphtheria. Acute laryngotracheobronchitis was believed to be a complication of the common cold caused by a parainfluenza virus (the virus was called a croup-associated strain in the 1960s). After having a runny nose and cough for a few days, the child with croup develops a stridor and difficulty breathing with each indrawn breath; on rare occasions, the child loses consciousness. Parainfluenza isolates (mostly type 1) account for $74.2 \%$ of the episodes of croup. Respiratory syncytial virus, influenza viruses $A$ and $B$, and Mycoplasma pneumoniae were the only other pathogens isolated in a study conducted in 1983 (3). Approximately 3\% of children younger than six years of age are affected by croup (4). As many as $1.3 \%$ of the affected children are hospitalized (4).

Croup is a clinical respiratory syndrome that is easy to diagnose because of its characteristic presentation. On occasion, a radiograph of the neck may be useful to differentiate croup from epiglottitis or a foreign body. Investigators at the Children's Hospital of Philadelphia, Pennsylvania used a lateral neck radiograph to diagnose croup, and claimed a sensitivity of $93 \%$ and a specificity of $92 \%$ (5).

The direct examination of the throat, when performed outside of the intensive care area, is controversial. The decreased incidence of epiglottitis has reduced this concern. Two case series have suggested that the direct inspection of the oropharynx did not cause any problems $(6,7)$.

In the 1970 s, emergency departments began to use nebulized epinephrine. It was found to be helpful in preventing hospital admissions (8). The dose was $5 \mathrm{~mL}$ of a solution of 1:1000 of L-epinephrine. A study that compared $5 \mathrm{~mL}$ of Lepinephrine with $0.5 \mathrm{~mL}$ of racemic epinephrine showed no difference between the two drugs (9). The problem with nebulized epinephrine was the rebound phenomenon, which occurred 2 to $4 \mathrm{~h}$ after treatment if a child was sent home too early. Many children had to return to the hospital and were admitted to the ward.

The use of glucocorticoids is the source of another controversy. Many clinicians were convinced that glucocorticoids were only effective in cases of spasmodic croup. Good evidence supports the use of glucocorticoids in treating moderate to severe croup of any etiology. Many studies used a croup scoring system to show improvement with various treatments and to compare treatment regimens. The Westley croup score, which is used most commonly, is an ordinal 
scale that measures clinical severity from 0 (best) to 17 (worst) on the parameters of stridor, retractions, air entry, cyanosis and level of consciousness (10).

Clinical improvement may be seen as early as $2 \mathrm{~h}$ after the use of glucocorticoids (11), but it is usually seen after $6 \mathrm{~h}$ (12). Dexamethasone has been given orally or parentally in many randomized, controlled trials. A meta-analysis showed that a single dose of dexamethasone of 0.3 to $0.6 \mathrm{mg} / \mathrm{kg}$ decreased the severity of symptoms and the need for hospital admission (13). For mild croup, a dose of dexamethasone of $0.15 \mathrm{mg} / \mathrm{kg}$ was shown to be effective (14). The oral dose or the intramuscular route has shown good results compared with placebo. To date, no studies have looked at the benefits of intramuscular therapy compared with oral treatment.

Because the use of dexamethasone proved to be effective in treating croup, it was natural to ask whether the inhaled route would also be effective. Budesonide is a synthetic glucocorticoid with twice the potency of beclomethasone, but a significantly lower systemic bioavailability because of its hepatic first-pass clearance (4). The effectiveness of nebulized steroid administration is debatable, and some studies have shown significant benefits. Klassen et al (15) studied nebulized budesonide for children with mild to moderate croup in the emergency department. At the end of a $4 \mathrm{~h}$ assessment period, patients in the budesonide group improved more and were discharged home earlier than those in the group that did not receive treatment (15). Griffin et al (16) systematically reviewed all placebo controlled, randomized trials of nebulized corticosteroid in the treatment of croup. They examined short term effectiveness and hospital admission rates. They concluded that both oral and nebulized steroid therapies are effective in reducing admission to hospital or the time spent in the emergency room (16).

Klassen (17) performed a systematic review that examined the effectiveness of glucocorticoids for the treatment of croup. A total of 24 randomized, controlled trials were identified, 15 of which were published after the meta-analysis by Kairys et al (13) in 1989. Glucocorticoids were associated with a significant improvement in the croup score used in the study $6 \mathrm{~h}$ after treatment. There was a significant decrease in the number of epinephrine treatments required after treatment with glucocorticoids, and emergency department stay was reduced by an average of $11 \mathrm{~h}$ (17). The authors could not detect any significant difference between budesonide and dexamethasone in clinical outcomes. A randomized trial that compared budesonide (2 mg) with dexamethasone (0.6 $\mathrm{mg} / \mathrm{kg}$ by mouth) failed to demonstrate any difference between the study groups (18). Johnson et al (19) also conducted a double-blind, randomized trial involving 144 children with moderately severe croup. They concluded that treatment with intramuscular dexamethasone or nebulized budesonide resulted in more rapid clinical improvement than a placebo, with dexamethasone offering the greatest improvement. Treatment with either glucocorticoid (budesonide or dexamethasone) resulted in fewer hospitalizations (19). In an editorial accompanying the Johnson et al paper
(19), Jaffe (20) concluded that children with croup who are seen in clinics or emergency departments should receive glucocorticoids. He wrote that there was good evidence for the efficacy of a single dose of either nebulized budesonide or dexamethasone given intramuscularly or orally. Jaffe (20) favoured oral dexamethasone because of its availability, ease of administration and cost (20). Klassen (17) recommends that, in the absence of further evidence, $0.6 \mathrm{mg} / \mathrm{kg}$ of oral dexamethasone should be the preferred treatment.

With the current standard of care, most patients with croup receive corticosteroids, regardless of whether they are seen in an emergency department or admitted as inpatients. The oral dose seems to be gentler than the intramuscular route, which is reserved for patients who cannot tolerate oral medication. The inhaled formulation is more expensive. The addition of inhaled epinephrine can be used if necessary, but, currently, it is not prescribed frequently because of the use of steroids.

In the future, studies will, certainly, show the benefits of steroids in the management of croup in the physician's office. Physicians should keep in mind the number of cases that resolve without any treatment before prescribing steroids for every case.

Finally, the difficulties, to date, in developing an effective vaccine against parainfluenza viruses should be resolved in the not too distant future.

\section{REFERENCES}

1. Lenney W, Milner AD. Treatment of acute viral croup. Arch Dis Child 1978;53:704-6.

2. Bourchier D, Dawson KP, Fergusson DM. Humidification in viral croup: A controlled trial. Aust Paediatr J 1984;20:289-91.

3. Denny FW, Murphy TF, Clyde WA Jr, Collier AM, Henderson FW. Croup: An 11 year study in a pediatric practice. Pediatrics 1983;71:871-6.

4. Klassen TP. Recent advances in the treatment of bronchiolitis and laryngitis. Pediatr Clin North Am 1997;44:249-61.

5. Mills JL, Spackman TJ, Borns P, Mandell GA, Schwartz MW. The usefulness of lateral neck roentgenograms in laryngotracheobronchitis. Am J Dis Child 1979;133:1140-2.

6. Diaz JH, Lockhart $\mathrm{CH}$. Early diagnosis and airway management of acute epiglottitis in children. South Med J 1982;75:399-403.

7. Mauro RD, Poole SR, Lockhart CH. Differentiation of epiglottitis from laryngotracheitis in the child with stridor. Am J Dis Child 1988;142:679-82.

8. Skolnik N. Treatment of croup. Am J Dis Child 1989;143:1045-9.

9. Waiisman Y, Klein BL, Boenning DA, et al. Prospective randomized double-blind study comparing L-epinephrine and racemic epinephrine aerosols in the treatment of laryngotracheitis (croup). Pediatrics 1992;89:302-6.

10. Westley CR, Cotton EK, Brook JG. Nebulized racemic epinephrine by IPPB for the treatment of croup: A double-blind study. Am J Dis Child;1978:132;484-7.

11. Geelhoed GC, MacDonald WB. Oral and inhaled steroids in croup: A randomized, placebo-controlled trial. Pediatr Pulmonol 1995;20:355-61.

12. Kuusela AL, Vesikari T. A randomized double-blind, placebo controlled trial of dexamethasone and racemic epinephrine in the treatment of croup. Acta Paediatr Scand 1988;77:99-104.

13. Kairys SW, Olmstead EM, O'Connor GT. Steroid treatment of laryngotracheitis: A meta-analysis of the evidence from randomized trials. Pediatrics 1989;83:683-93. 
14. Geelhoed GC, Turner J, MacDonald WBG. Efficacy of a small single dose of oral dexamethasone for outpatient croup: a double blind placebo controlled clinical trial. BMJ 1996;313:140-2.

15. Klassen TP, Feldman ME, Watters LK, Sutcliffe T, Rowe PC. Nebulized budesonide for children with mild to moderate croup. $\mathrm{N}$ Engl J Med 1994;331:285-9.

16. Griffin S, Ellis S, Fitzgerald-Barron A, Rose J, Egger M. Nebulized steroid in the treatment of croup: A systematic review of randomised controlled trials. Br J Gen Pract 2000;50:135-41.
17. Klassen TP. Croup. A current perspective. Pediatr Clin North Am 1999;46:1167-78.

18. Klassen TP, Craig WR, Moher D, et al. Nebulized budesonide and oral dexamethasone for the treatment of croup: A randomized controlled trial. JAMA 1998;279:1629-32.

19. Johnson DW, Jacobson S, Edney PC, Hadfield P, Mundy ME, Schuh S. A comparison of nebulized budesonide, intramuscular dexamethasone, and placebo for moderately severe croup N Engl J Med 1998;339:498-503.

20. Jaffe DM. The treatment of croup with glucocorticoids. N Engl J Med 1998;339:553-4.

\section{INFECTIOUS DISEASES AND IMMUNIZATION COMMITTEE}

Members: Drs Upton Allen, The Hospital for Sick Children, Toronto, Ontario; H Dele Davies, Division of Infectious Diseases, Alberta Children's Hospital, Calgary, Alberta; Joanne Embree, The University of Manitoba, Winnipeg, Manitoba, (chair); Joanne Langley, Department of Pediatrics, IWK Health Centre, Halifax, Nova Scotia; Mireille Lemay, Department of Infectious Diseases, Sainte-Justine Hospital, Montréal, Québec; Gary Pekeles, The Montreal Children's Hospital, Montreal, Quebec (director responsible)

Consultants: Drs Noni MacDonald, Faculty of Medicine, Dalhousie University, Halifax, Nova Scotia; Victor Marchessault, Cumberland, Ontario Liaisons: Drs Scott Halperin, Department of Pediatrics, IWK Health Centre, Halifax, Nova Scotia (IMPACT); Susan King, Division of Infectious Diseases, The Hospital for Sick Children, Toronto, Ontario (Canadian Paediatric AIDS Research Group); Monique Landry, Direction de la santé publique de Laval, Laval, Québec (Public Health); Larry Pickering, Centre for Pediatric Research, Norfolk, Virginia, USA (American Academy of Pediatrics)

Principal author: Dr Victor Marchessault, Cumberland, Ontario

The recommendations in this note do not indicate an exclusive course of treatment or procedure to be followed. Variations, taking into account individual circumstances, may be appropriate. 


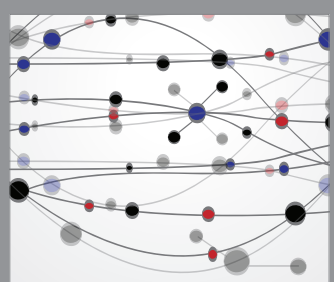

The Scientific World Journal
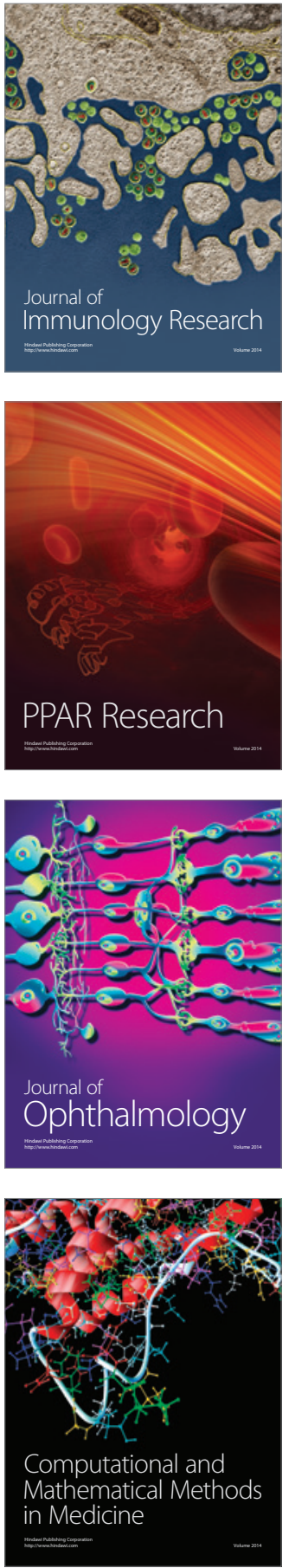

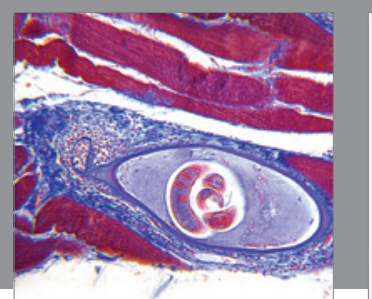

Gastroenterology Research and Practice

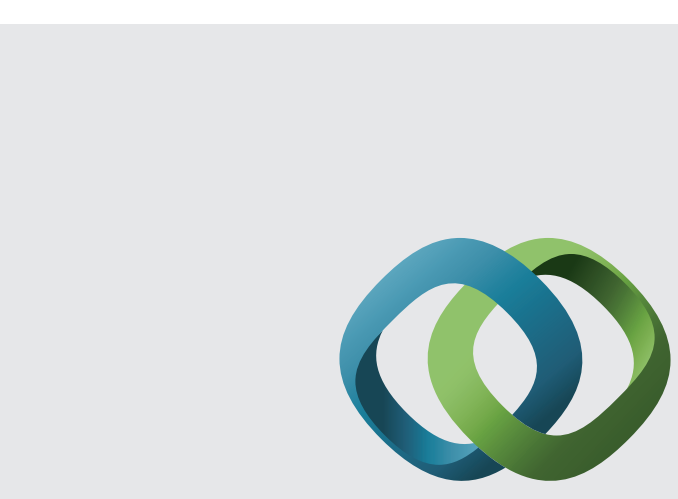

\section{Hindawi}

Submit your manuscripts at

http://www.hindawi.com
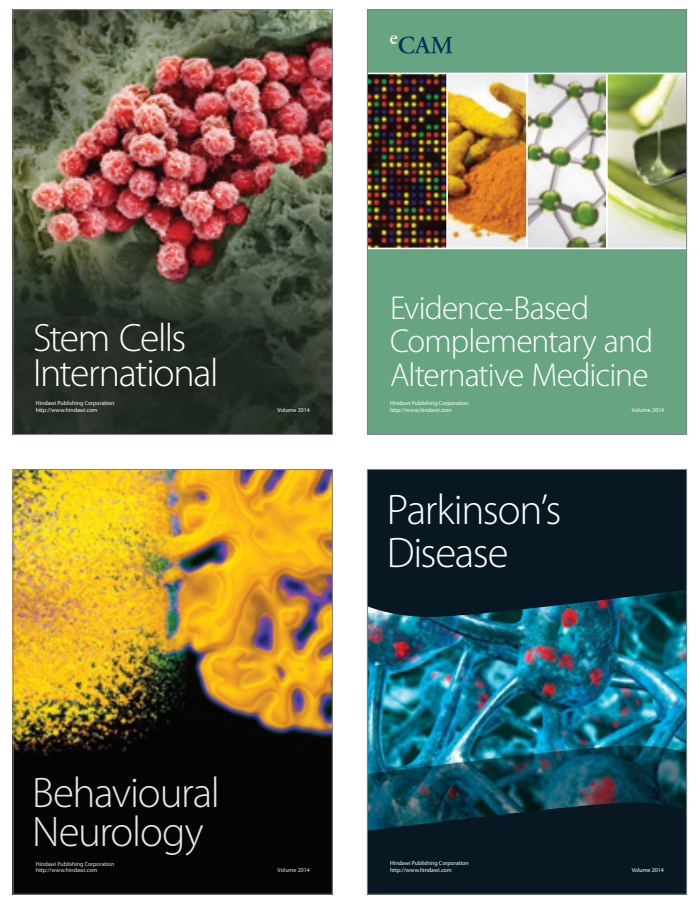
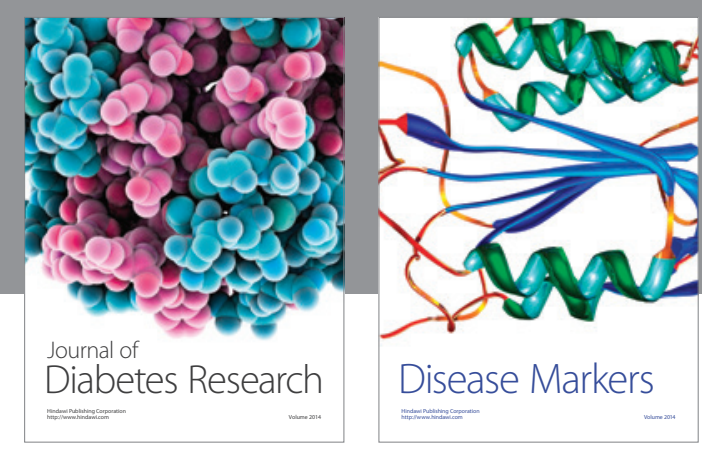

Disease Markers
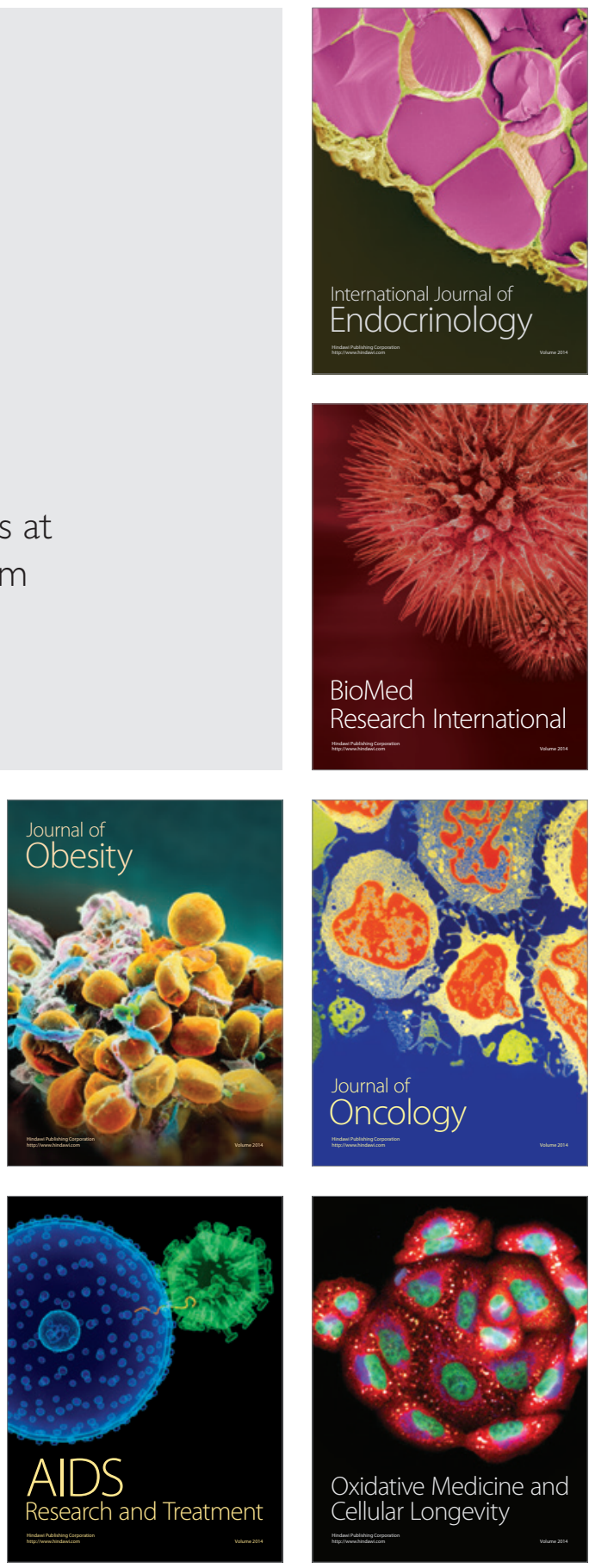